\title{
The Augmented Commons: How Augmented Reality Aids Agile Self-Organization
}

\author{
Abigail Devereaux \\ George Mason University
}

\begin{abstract}
Augmented reality (AR) is a real-time, interactive user experience that inserts virtual computer-generated elements into a user's physical environment. I provide examples from existing $\mathrm{AR}$ applications and conceptualize how AR strengthens self-organization and enables the emergence of polycentric loci of private governance, or agile selforganization. Examples include information-enhancing overlays, automatic language translation, individualization and privatization of personal and worker safety provision, reduction of emergency response times, and enrichment of education with overlays and holograms. I conclude that AR technologies erode policy rationales for intervention by solving public problems with a greater number of less-costly private solutions.
\end{abstract}

\section{JEL Codes: O33, O35, H41, H11}

Keywords: augmented reality, private governance, polycentricity, public goods, augmented commons, agile self-organization

\section{Introduction}

Augmented reality (AR) is a real-time, interactive user experience that inserts virtual, computer-generated elements into a user's physical environment. Examples of augmented reality are digital first-down lines on a football field, the popular game Pokémon Go! where collectable monsters spawn in a user's environment, and spokenword translation apps like Google Translate (Wingfield and Isaac 2016). AR devices capture and identify "scenes" as a user moves through the world. The devices utilize the internet of things (IoT), a digital, online mesh of connected devices such as sensors and cameras. AR devices gather contextual information from a user's camera, GPS, and microphones, and AR uses the IoT to get data from environmental sensors, traffic cameras, and other datacollection devices in the user's environment (Shafer, Brumitt, and Cadiz 2001). AR software produces scene-relevant holograms, sounds, and other sensory inputs, then projects those elements 
through the user's display to literally augment the experience of the world.

Though AR is in its relative infancy, it won't be for long. The emerging hegemony of IoT technologies, whose number of devices was at seven billion in 2018 and is projected to triple by 2025 (Lueth 2018), will make AR easier to develop and deliver to users (Ip 2016). $\mathrm{AR}$ as a concept is far older than most people realize. It dates to the conceptualization of the head-up display, which shows virtual information in the user's line of sight. The first concept of AR was drafted for British military pilots during World War II in the form of a piece of glass fixed in front of the pilot to display radar information on an artificial horizon (Johnson 2019). Mobile augmented reality systems weren't developed until Ivan Sutherland's suspended headmounted display in 1968, but processing power at the time limited what a user could see to simple wireframes.

Augmented reality as a term is generally considered to have been coined by Caudell and Mizell (1992) in reference to a head-mounted display showing computer graphics overlaid on the factory floor. Around this time, Louis Rosenberg developed the first fully immersive AR system for the US Air Force's Armstrong Labs. In 2000, Bruce Johnson developed the first AR game, AR Quake. By the early 2000s, interest in and development of AR were picking up, enabled by an exponential increase in computing power and the refinement and ubiquity of mobile wireless devices.

A pilot's experience of overlays in the line of sight is a different experience than that of a smartphone user viewing overlays through a screen. An overlay viewed through a device that moves when your head moves can become a much more powerful extension of your senses than squinting at overlays through the tiny window of a cellphone screen or while aiming a tablet at the world. Freeing a user's hands to interact with holograms and overlays immerses them in a new world where holograms and overlays are truly part of their environment. The Microsoft HoloLens, released in 2016, was one of the first fully wireless general-use AR headsets. AR headsets allow their users to see and interact with virtual elements in the physical world. Wearables such as Bluetooth headphones and wristbands give their users even more dynamic ways of experiencing the sound and feel of virtual elements in their environment.

As the AR revolution is still nascent, the consequences of using AR to aid self-organization and market exchange have not yet been realized. Only recently have they begun to be discussed (see, e.g., 
Thierer et al. [2015]). My contribution to the AR discussion comes from the perspective of the economics of undesigned orders. ${ }^{1} \mathrm{By}$ virtue of the growing ubiquity of media through which AR can be experienced, AR may be able to assist in the private provision of public goods given the advantages AR grants to users-such as ameliorating information asymmetries and enabling better monitoring and communication. AR provides users with information-enhancing overlays; automatic language translation; the ability to individualize and potentially privatize the provision of personal and worker safety; the ability to reduce emergency response times; and an education enriched by overlays and holograms. AR is by and large coordinative; it can help to realize several of the institutional and environmental design principles positively correlated with the private provision of public goods as noted by Elinor Ostrom (2010). I will show that AR has the potential to aid agile self-organization, or self-organization that enables polycentric loci of private governance to emerge.

The paper is organized as follows. Section 2 covers commonly invoked economic rationales for policy making-namely, theories of market failure and of public goods. I discuss Ostromian design principles of solutions to public goods problems and the concept of polycentric governance. Section 3 introduces agile action, agile policymaking, and agile self-organization. I marry the idea of agile selforganization to the concept of polycentric governance in an explication of what I call agile self-governance. Section 4 explains how augmented reality technologies help coordinate agent plans, particularly at the level of self-organization, and how AR aids agile self-governance by enabling several of Ostrom's design principles for self-organized solutions to common-pool resource problems. Section 5 concludes.

\section{Policy Rationales}

Working within a strict neoclassical theory of welfare economics, market failures abound-not surprising, since the neoclassical model counts as a failure any deviation from informational perfection. ${ }^{2}$ Neoclassical economists have adopted the efficiency of the market mechanism exemplified by the welfare theorems as both scientific and normative ends of economics. Public goods and market failure

\footnotetext{
${ }^{1}$ See especially Hayek ([1973] 2012) on the concept of catallaxy.

2 This methodological attitude is exemplified in Grossman and Stiglitz (1980]) with respect to the economics of information, and more recently, in Thaler and Sunstein (2008) with respect to behavioral economics.
} 
theories in the neoclassical tradition aspire to the perfection of this mechanism. ${ }^{3}$

Too much intervention may crowd out voluntary cooperative solutions to public goods problems (Frey and Oberholzer-Gee 1997; Reeson and Tisdell 2008); too little intervention may leave public goods underprovided by the unencumbered market (Acemoglu 2005). Policies and laws substitute for altruism, societal norms, and organization-based rewards and penalties for good and bad behaviors (Bowles and Polania-Reyes 2012). Self-organization depends on myriad, typically nonreproducible circumstances that can be damaged by intervention; furthermore, a mix of formally independent public and private decision-making loci tends to be more efficient than pure public governance (Ostrom 1990, 2010). Results using information choice theory support the greater efficiency of polycentric decisionmaking, as information goods can be modeled like commodities whose quality increases when there is more competition (Koppl 2018, pp. 196-99; Milgrom and Roberts 1986; Whitman and Koppl 2010).

Technological changes can degrade policy rationales by providing new ways to solve old public goods problems. "Technology sets what may be called an intellectual half-life on policies and their justifications," note Foldvary and Klein (2002, p. 82). Innovations tend to complexify economic life by forging new connections between old institutions and products and by severing old connections through the provision of new institutions and products. We may grant the original policy the benefit of the doubt for broadsightedness and attention to detail when enacted. But it follows that simple growth due to innovation means even the best-crafted policies have both a rationale half-life and an effectiveness half-life. If technology trims transaction and production costs-by making it easy to charge users, define and enforce property rights, exit and utilize substitutes, gather information, gain assurance of quality and safety, and enter and compete in markets-then the invisible hand works better than policy (Foldvary and Klein 2002, p. 83).

Policy makers, like private actors, face a time horizon beyond which they cannot see. Interventions may lock in the supremacy of methods and institutions that are not as efficient as the market will

\footnotetext{
3 The pure market mechanism has come under attack by some economists. A recent example is Shiller and Akerlof's Phishing for Phools (2015), where the pure market mechanism is implicated in a producer scheme to influence individual preferences rather than service them.
} 
eventually be able to bear, given the immutable trend of technological development in presenting new ways to solve old problems. Policy interventions today could change the nature of political institutions tomorrow, tilting the balance of political power in favor of groups or norms the researcher deems unfavorable (Acemoglu and Robinson 2013). I contend that interventions tend to block or slow one of the greatest advantages of the market process: its agility to changing circumstances.

\section{Agility}

Agility is adaptability to changing conditions. I am especially interested in how augmented reality can increase the agility of social systems to self-organize solutions to public goods problems, and I call this process agile self-organization. Agile action in complex social systems is typically defined in a way that evokes what mainline economists might call Kirzernian entrepreneurial action, where individuals attempt to build a better mousetrap by applying old solutions to new problems or new solutions to old problems (Kirzner 1997; Room 2016, p. 82). Similarly, I analogize agile action as problem-solving or "satisficing" (Newell and Simon 1972; Simon 1996), extending the validity of my analysis to bounded rationality regimes.

Stressing that agile action is analogous to entrepreneurial action is useful because it lends structure to the knowledge individuals rely on to solve problems. Individuals do not simply engage in habitual rulesfollowing behavior, traversing well-worn behavioral paths. Agile action requires forging new paths, integrating new knowledge into previous knowledge-adding to, reforming, and perhaps also deleting old rules in a way that may significantly change not only how someone solves new problems, but how they solve old problems as well.

It is incumbent on us to embed individual action in an institutional context that is constantly changed on the margins by the individuals themselves. We begin by placing individuals in a dynamic social network whose structure represents their relationships over time. Institutions in network analysis constitute a broad category that describes both the network's features and its rules of behavior. Examples of network features are community clusters and the placement of an individual near an informationally powerful "structural hole," which typically occurs on bridges between community clusters (Easley and Kleinberg 2010; Burt 2009; 
Granovetter 1973). Behavioral rules define how an individual's utility, income, or payoff changes as they interact with their network neighbors. For example, individuals could play a payoff-maximizing game with their network neighbors, utilize a heuristic like copying whatever their neighbors do on average, or employ a mixture of strategy and heuristics (Jackson and Zenou 2010; Gigerenzer and Todd 1999; Barkoczi and Galesic 2016).

Both network structure and rules influence information diffusion. Depending on the network structure and the individuals in the network, different ecologies of behavioral rules may develop. The nature of these ecologies describes both how individuals in different communities self-organize and how those communities organize between themselves. The institutional context is influenced by emergent and evolutionary processes over time and is subject to direct, albeit imperfect, manipulation by influential agents.

As an example, imagine a producer connected to upstream suppliers, downstream customers, employees, and even abstract agents like the IRS. This producer may be the original author of some of these relationships; she may have replicated some relationships based on a preexisting template; she may have had some relationships imposed upon her; and she may be banned from making other relationships. Suppose she starts a business that is an offshoot of a family member's business. She is able to replicate some of the relationships that form her family member's production network, but has to forge new connections to differentiate her product. She must report her earnings and other numbers to the IRS, and she may be banned from exporting her products to some localities.

Some agents have more relationships than others. The abstract IRS agent has many more connections than the average tax filer or business owner. Generally, this sort of network can be made precise using graph theory and analyzed using graph theoretical measurements and statistics that take into account how the coupling of individual actions affects individual attributes such as income or utility (see especially Jackson [2010] for a primer on social network theory). Contrast this form of analysis with standard linear regression, where coupling confounds the accuracy of measured relationships (Easley and Kleinberg 2010).

Suppose agents within the institutional network wish to change it somehow. The polycentric nature of decision-making implies that there is more than one channel through which changes can be made. There isn't only one way to get changes right; many solutions exist, 
and good solutions make better use of time and place information (Ostrom 1990). Agents can change institutional structures in three ways: (1) in an unplanned evolutionary/emergent manner, (2) as a planned coordination between agents, and (3) as a planned imposition of one or more agents on other agents. ${ }^{4}$ Externalities and spontaneous orders fall into the first category, self-organization or private governance falls into the second category, and planning or public governance falls into the third category. Table 1 provides a summary.

Table 1. Three ways agents can change institutional structures

Institutional change Order

Unplanned/evolutionary Externalities; spontaneous orders

Planned coordination among agents Self-organization; private governance

Planned imposition on agents by other agents

Planning; public governance

Individuals in real social processes engage in one of the three channels of institutional change as the process unfolds, with some individuals acting along each channel at any cross-section in time. Individual actions in one channel may coordinate or conflict with actions in another, like how evolutionary actions with externalities may conflict with planned impositions to remove those same externalities.

Actions taken along one channel may be self-reinforcing. For example, planned impositions such as policies may alter the features of the institutional network in a way that increases the influence of already-influential agents, which then incentivizes all agents to shift resources from unplanned self-organizing structures to planned impositions (Beito 2003). The recognition of how planned impositions can perniciously interact with the institutional network reflects the basic lesson of public choice economics. The institutions of public governance interact and compete with the institutions of private governance.

\footnotetext{
${ }^{4}$ Though these categorizations were not drawn from Buchanan and Tullock (1962), they are nearly indistinguishable from the three ways to make policies as identified in that work.
} 
Furthermore, interactions between the institutions of public and private governance occur within an ecology of policies and individual plans. Plans and policies are not initiated simultaneously but are implemented as other plans and policies are already in place or unfolding (Wagner 2016; Room 2011). Room (2011, p. 135) notes in particular that an awareness of the policy ecosystem and its interaction with the ecosystem of individual plans and self-organized solutions would grant policy makers the ability to craft policy in an agile way that can better avoid negative unintended consequences, what Room calls agile policy-making. And I call self-organized solutions that account for interactions with other plans and self-organized solutions agile self-organization. New technologies such as AR increase the agility of decision-makers in governance loci. How a technology aids agility in each type of governance locus is an epistemological question, and is summarized in table 2 .

Table 2. How technology aids agility in governance loci

\begin{tabular}{llll} 
Institutional change & Order & $\begin{array}{l}\text { Knowledge } \\
\text { utilized }\end{array}$ & $\begin{array}{l}\text { Decision } \\
\text { logic }\end{array}$ \\
Unplanned/evolutionary & $\begin{array}{l}\text { Externalities; } \\
\text { spontaneous } \\
\text { orders }\end{array}$ & Constitutive & $\begin{array}{l}\text { Undergo } \\
\text { complex } \\
\text { evolution of } \\
\text { interacting } \\
\text { variables }\end{array}$ \\
\hline $\begin{array}{l}\text { Planned coordination } \\
\text { among agents }\end{array}$ & $\begin{array}{l}\text { Self- } \\
\text { organization; } \\
\text { private } \\
\text { governance }\end{array}$ & $\begin{array}{l}\text { Constitutive; } \\
\text { speculative }\end{array}$ & $\begin{array}{l}\text { Conduct } \\
\text { economic } \\
\text { calculation; } \\
\text { learning; } \\
\text { adaptation }\end{array}$ \\
\hline $\begin{array}{l}\text { Planned imposition on } \\
\text { agents by other agents }\end{array}$ & $\begin{array}{l}\text { Manipulation; } \\
\text { coercion; public } \\
\text { governance }\end{array}$ & Speculative & $\begin{array}{l}\text { Infer models } \\
\text { of } \\
\text { relationships; } \\
\text { update models }\end{array}$
\end{tabular}

Planned imposition is speculative since it is conducted about an agent for which the policy maker (1) has no access to its preferences and local knowledge, and (2) will bear the rewards and costs of the policy in a unique way not borne by the policy maker. That is, policies are not naturally constitutive in that policy makers do not learn directly how well a policy worked for its intended target; they 
can only observe higher-level trends that may obscure important effects experienced by any given target.

\section{Augmented Reality Is Coordinative}

Public governance and public solutions are costly and come with deleterious side effects. One example is feedback loops that exacerbate dependence on entitlements once entitlements have been established and that increase the amount of resources transferred from entrepreneurial problem-solving to dissipating political rents. Self-organization and private governance are more efficient ways to solve coordination problems, when possible.

Elinor Ostrom is perhaps best known for her work on selforganized solutions to commons problems. Ostrom discovered that the rules agents used to manage common-pool resources were unexpectedly diverse, with no single common thread running through the institutional rules that made for successfully selforganized communities. Instead, such communities are characterized by a number of institutional regularities: ${ }^{5}$

1A. User Boundaries: Clear and locally understood boundaries between legitimate users and nonusers are present.

1B. Resource Boundaries: Clear boundaries that separate a specific common-pool resource from a larger social-ecological system are present.

2A. Congruence with Local Conditions: Appropriation and provision rules are congruent with local social and environmental conditions.

2B. Appropriation and Provision: Appropriation rules are congruent with provision rules; the distribution of costs is proportional to the distribution of benefits.

3. Collective-Choice Arrangements: Most individuals affected by a resource regime are authorized to participate in making and modifying its rules.

4A. Monitoring Users: Individuals who are accountable to or are the users monitor the appropriation and provision levels of the users.

\footnotetext{
${ }^{5}$ List quoted from Ostrom (1990, p. 422) and developed based on Ostrom's earlier research by Cox, Arnold, and Villamayor-Tomás (2009) (bold added).
} 
4B. Monitoring the Resource: Individuals who are accountable to or are the users monitor the condition of the resource.

5. Graduated Sanctions: Sanctions for rule violations start very low but become stronger if a user repeatedly violates a rule.

6. Conflict-Resolution Mechanisms: Rapid, low-cost, local arenas exist for resolving conflicts among users or with officials.

7. Minimal Recognition of Rights: The rights of local users to make their own rules are recognized by the government.

8. Nested Enterprises: When a common-pool resource is closely connected to a larger social-ecological system, governance activities are organized in multiple nested layers.

Individuals engage in agile self-governance when they develop or exploit institutional regularities in ways that account for interaction with other self-organized structures and policies. As we become more integrated with our devices, we have the opportunity to experience our world in deeper ways than allowed for by our human senses, ways that assist work, family life, and education, and ways that will greatly aid knowledge through the kind of information users display on top of their world, in their ears, ${ }^{6}$ in their eyes, ${ }^{7}$ and, perhaps eventually, in their brains. ${ }^{8}$

As a function of this augmentation and deepening of moment-tomoment experiential data, AR will assist us in organizing solutions to coordination problems by promoting the creation and exploitation of Ostrom's institutional regularities. Augmented reality is a coordinative technology in that it can be used to help coordinate agents' various economic and social ends. Since AR is deployed using the internet of things, AR as a coordinative technology serves the dual function of augmenting user experiences and lowering the

\footnotetext{
6 Bose is launching audio-augmented reality glasses, centered on soundscapes (Gartenberg 2018).

${ }^{7}$ Kim et al. (2015) have a patent pending for "smart contact lenses for augmented reality and methods of manufacturing and operating the same"; Omega Ophthalmics offers an AR eye lens implant targeted at people seventy and older (Buhr 2017).

${ }^{8}$ Brain interfaced augmentation is known as "neuroreality" and is, as a technology, progressing faster than most people expected. In 2017, Elon Musk launched Neuralink, a basic brain-computer interface (Statt 2017).
} 
transaction costs of connecting users, thus enabling the easy dissemination and updating of collective-choice arrangements (see no. 3, above) and the imposition of graduated sanctions (5) on violators. AR provides individuals with information about their environments through sound, visuals, and other sensory inputs, which generally helps to establish user boundaries (1A), maintain congruence with local conditions (2A), monitor users (4A), and monitor resources (4B). Environments include other people, objects, buildings, weather conditions, road conditions, time-sensitive event information (like happy hours, sales, and public talks in the area), and even aggregate measurements like local demographic information and public sentiment.

\section{A. Augmenting Information}

Technological developments can ameliorate information asymmetries. Consider a consumer who wants a high-quality watch for a moderate price, and would therefore like to coordinate her ends with the ends of producers who sell high-quality watches at moderate prices. The consumer may find this coordination difficult if she doesn't know who sells such products or how to rate their quality. Before the near-ubiquitous star-rating system, items sold online began at a distinct disadvantage to products sold in stores, because online shoppers could not employ standard methods of determining the product quality such as touching the item, trying it out, or talking to store associates. Star ratings developed advantages that traditional quality-determination methods did not have, through crowdsourcing the experiences of product users over time. Star ratings augmented online product descriptions in a way that assisted consumers and producers in solving their coordination problem (Thierer et al. 2015).

How might AR help consumers and producers solve coordination problems? By importing crowdsourced star ratings into the physical store. Smartphone AR apps use developer toolkits like Apple's ARKit and Google's ARCore and built-in cameras to become windows to virtual content. One of the biggest ways in which AR is changing shopping is by allowing users to virtually "try" products before buying. This means seeing how furniture might fit and look in a room (examples are Amazon's and IKEA's shopping apps), how makeup products might look applied to your face (Sephora's Virtual Artist app) and how clothes may fit your body (Zeekit's existing app and Amazon's app-in-progress). And although many of the following are still in the conceptual phase, AR can also augment products with 
star ratings, reviews, user-tailored ingredient and macro lists for diets and allergies, price comparisons, provenance, which items are new and which are on sale, and whatever information a user might need or want to know in order to better coordinate her ends with producers' ends. One example of a point-and-view data overlay app that enhances shopping is Pinto, aimed at diabetics in particular and capable of displaying a food item's total carbohydrates, fats, and other macronutrients. Calorie Mama, though not exactly AR, is a "smart camera" app that analyzes photos of food to estimate their calories and nutritional content. As pattern matching and processing get faster, it's reasonable to expect real-time food recognition with nutritional overlays.

Hyundai was the first car company to release its user manual as an AR app, where a user loads the app onto a tablet or phone and points the device's camera toward any part of the car (Johnson 2015). The app then labels each element in the camera's view, as shown on the tablet screen, and users can tap the labels to retrieve more information about the part's function and maintenance. It is easy to envision how AR could ameliorate the "lemons" problem (Akerlof 1970)_buying a used car could be as simple as pointing your device's camera at a prospective purchase's vehicle identification number and retrieving a CarFax report along with data on any deviations between the car on the lot and an ideal model.

\section{B. Augmenting the Ability to Monitor Use}

AR can provide ways to monitor and track the use of a commonpool resource. Global Fishing Watch maps global fishing activity using satellite tracking data provided by fishing boats and machine learning to extrapolate unreported patterns of fishing (Google 2019; Sullivan 2016). When public goods usage becomes easier to monitor and sanction, it becomes easier for organizations to manage.

Take the example of a public grazing field. Suppose someone develops an app that virtually shades which sections of grazing land have been utilized by legitimate contributors to the maintenance of that land and which sections have been utilized by interlopers. Perhaps the app uses GPS data to track legitimate users and satellite images to compare expected use with actual use, with overuse indicating illegitimate grazing. Shepherds registered to use the field could conceivably utilize an app that automatically updates a list of who is using how much of the field and whether there are new users. This grazing tracker app would aid in establishing user boundaries 
(1A) and in monitoring users (4A), thereby enhancing users' ability to monitor the resource (4B). Enhancing the trackability of commonpool resource usage gives the community a tool to extricate itself from a prisoner's dilemma situation. Enhancing trackability of usage enhances agile self-organization.

\section{Decentralizing Decision Loci}

Polycentricity of decision loci is related to more efficient provision of policing (Ostrom 2009; Ostrom and Parks 1999, p. 290). Augmented reality can enhance the provision of public safety both directly, by improving existing solutions, and indirectly, by strengthening the ability of polycentric loci of service provision to emerge. AR technology can improve the situational awareness of security personnel so they can assess and react to situations much more quickly and accurately using speaker-recognition technology; realtime language translation; floor plan and street overlays; advanced optics for lip-reading; thermal imaging to detect lying during an interrogation; traffic information; visualization of crime scene data; and tracking of crimes and monitoring of high-crime areas utilizing the IoT (Cowper and Buerger 2017). Facial recognition and contextualization are two common uses of AR technology that can assist in monitoring users (4A) and attaining congruence with local conditions $(2 \mathrm{~A})$, though it remains unclear the extent to which users may be harmed by centralized use of augmented reality for facial recognition by police, as in China (Vincent 2018).

Traditional crime maps are being integrated into augmented applications, enhancing congruence with local conditions (2A). SpotCrime was the first app to do so, integrating overlays into its iPhone app as early as 2010 (SpotCrime staff 2010). Free To Be is a mapping app launched out of Melbourne, Australia, to crowdsource areas of the city and sources of transportation where women have experienced physical, verbal, and sexual harassment (Day 2016). Women tag geographic locations with happy- or sad-face icons to indicate places where they felt safe from harassment and places where they experienced actual or anticipated danger. Most tags are submitted with textual explanations and indicate whether the tag refers to daytime or nighttime. Women report being physically assaulted, areas where there is poor lighting at night, and places where aggressive or drunk people hang around. AR tech could be added to devices such as fitness trackers and smartphones and could 
provide haptic feedback warnings (a type of AR) when wearers enter unsafe areas.

\section{Augmenting Congruence with Local Conditions}

AR can also aid the provision of industrial and workplace safety, another way of enhancing congruence with local conditions (2A), monitoring users (4A), and monitoring a resource (4B). Manufacturing and supply chains benefit from augmented reality to help spot problems in a malfunctioning machine. Supply chain managers and repair technicians can improve the efficiency of logistics or detect malfunctions that might lead to an accident by wearing head-mounted displays that provide real-time information on the operation of each production component and a layout of the entire production process. Worker safety can also be enhanced by "vision picking" AR technology that helps workers locate and monitor items, gauges, and processes in warehouses and factories, lessening the need for and cost of public safety inspectors (DHL 2016).

The DAQRI head-mounted display is an AR headset that engages in pattern recognition on the thermodynamic spectrum, giving workers the ability to pinpoint possible safety issues in pipes and machines at a glance. Over 40 percent of Occupational Safety and Health Administration (OSHA) compliance officers are industrial hygienists, whose jobs are to monitor industrial conditions on the factory floor and in other situations that could pose a threat to worker safety and health (OSHA 2005). In 2016, OSHA had a budget of $\$ 592.1$ million, with about 82 percent of the budget allocated to enforcement at a federal level (OSHA 2016). Suppose that compliance inspections are just half of what OSHA does. By relying on AR rather than OSHA, upwards of $\$ 242.7$ million could be reallocated to other uses in an industrial sector that can, with much less cost and better epistemological efficiency, monitor its own industrial hygiene. Due to the high cost of compliance with safety regulations, producers will be incentivized to bring the IoT to the factory floor by adopting AR technology. Widespread adoption could feed back into the political mechanism, lessening the public mandate to monitor and regulate factory safety as this locus of self-governance is empowered by AR.

Driver safety is another area whose locus of self-governance will be empowered by AR, mostly through enhancing congruence with local conditions $(2 \mathrm{~A})$, but also perhaps through user boundaries (1A) 
and resource boundaries (1B) as augmented reality could make it easier to manage traffic and road conditions on both public and private roads. The mobile app Waze enhances the user's environment with alerts about debris on the road, accidents, traffic, and nearby speed traps. Other AR driving applications place road and navigation information in the driver's primary field of view-similar to how head-up displays augment pilot navigation (Kim and Dey 2009). Augmenting the driver's field of view is less distracting than relying on traditional navigation devices like on-board GPS screens (Medenica et al. 2011). British car brand MINI's Augmented Vision plans to provide drivers with relevant information in their field of sight, including head-up displays of speed and speed limits; "contactanalogue navigation arrows 'on' the road"; notations of interesting features along the route, such as open parking spaces; SMS messages; and even the ability to "see through" the car's blind spots so that external obstacles are viewable (BMW 2015). AR could even track the position of a driver's head to determine if he or she was distracted and trigger an alert to the driver to refocus (Murphy-Chutorian and Trivedi 2010). AR and the IoT could make constant state- and federal-level "fine-tuning" of road safety regulations obsolete.

Disaster relief intuitively fits the definition of a public good, as its overall positive effects are nonexcludable, though relief services delivered to disaster victims are typically nonrival (Shughart 2008). Contrary to this public-good intuition, however, private organizations have often outperformed public organizations in providing disaster relief (Coyne and Lemke 2011; Coyne 2013, p. 202). AR can help further move the locus of governance in disaster relief toward selfgovernance, as AR tech can assist relief and rescue workers in determining the best places to dedicate their resources, aiding in appropriation and provision (2B), monitoring users (4A), monitoring the resource $(4 \mathrm{~B})$, and enhancing congruence with local conditions (2A). Structural damage can be assessed by superimposing real and augmented views of a building, or could be deduced by pattern matching on images of the building before its destruction, helping to measure the damage or pinpoint areas where humans may be trapped (Leebmann 2004; Kamat and El-Tawil 2007).

\section{E. Augmenting Knowledge Acquisition and Use}

Knowledge is considered a pure public good, as it is nonsubtractable and difficult to exclude. AR has the potential to significantly change, and is already changing, how workers are trained. The DAQRI head- 
mounted display mentioned earlier delivers instructional overlays so that workers can be trained remotely and more precisely. Students could benefit from AR in a similar fashion, with overlays directing their attention to the most important parts of the lecture, highlighting the flow of a mathematical proof, or providing interaction with holographic human organs, steam engines, or scaled-up versions of plant cells.

The possibilities are as limitless as the medium. Long-gone historic artifacts and extinct species are already being brought back to life in holographic form in some museums (Rieland 2012). Teacher truancy in India, estimated at 23.6 percent and a cost of $\$ 1.5$ billion a year (Muralidharan et al. 2017), could be solved in districts that have electricity and cell phone saturation by sharing teachers as holographic images via AR, thus enabling Ostromian collectivechoice arrangements (3) for the provision of education.

\section{F. Augmenting Self-Organization}

Another design principle, conflict-resolution mechanisms (6), could be exemplified by robust AR solutions as AR technology becomes cheaper and more pervasive. AR provides a seamless way to experience the constant connectivity and real-time data updating emblematic of the internet of things. Compared to paper-based methods, internet technologies reduce the cost of organizing people with similar interests, characteristics, and goals. But the cost isn't zero. Users incur a search cost when finding a suitable online forum (blogs, social media aggregators, newsgroups, message boards) and a time cost in getting to know other members, developing one's own profile, and logging interests, opinions, activities, and other grouprelevant data. By collecting, analyzing, and publishing data automatically and in real time, AR can reduce individuals' required investment. As such, the arena of conflict resolution becomes the augmented commons. Transgressions are logged automatically and in real time, triggering punishments and penalties. Disputing a punishment is as easy as messaging all users in parallel and requesting an exception that can be granted through a simple response to the message. Wherever users are in space, they can gather in augmented reality to discuss rule changes. Self-organized solutions thereby become less brittle to conflict. 


\section{Conclusion: The Augmented Commons}

The use of augmented reality holograms, soundscapes, and haptic feedback in daily life could make it easier for users to grok the context of any kind of social or individual problem they wish to solve by enriching the decision-making space with additional cues and information. Even though its most robust uses are yet to come, augmented reality's pervasive realization is inevitable given that AR can easily serve as the primary delivery system of the data collected by our increasingly many interconnected devices.

AR cleaves nicely to several of Elinor Ostrom's design principles for self-organized solutions to common-pool resource problems. AR enhances monitoring in an obvious way, by enhancing trackability of usage. Monitoring the condition of the resource becomes less costly using $\mathrm{AR}$ in combination with the internet of things. AR also yields better results when a resource's users are its monitors, due to epistemic considerations, and by enhancing the ability of individuals in particular to better apprehend and observe aspects of that world that are important to them. AR allows and encourages users of resources to monitor the condition of those resources.

AR can be utilized in a coordinative fashion by stakeholders seeking to further their subjective ends. Possibilities for the discoordinative use of AR abound, however, if collective-choice arrangements are monopolized by a nonstakeholder to impose his ends upon others. Thus, while we applaud the use of distributed forms of AR, we must also note the potential abuses of AR-for example, for facial recognition by police officers (as in China).

The augmented commons is the space in which AR helps individuals and groups solve coordination problems without any need for public intervention. The rise of $\mathrm{AR}$ technologies is bound to erode some policy rationales for public goods provision and lower the transaction costs of developing self-organized solutions to public goods problems. The erosion of rationales for intervention will occur in spite of how deeply a good is entrenched in public provision, as we have seen from the success of ride-sharing apps despite a historically entrenched and powerful taxi lobby. As Koopman, Mitchell, and Thierer note, "The key contribution of the sharing economy, however, is that it has overcome market imperfections without recourse to traditional forms of regulation" (2015, p. 530).

The epistemological question of whether agile self-organization leads to better governance outcomes than agile policy-making was perhaps addressed best by F. A. Hayek's Nobel-prize-winning work 
on the division of knowledge and its use in society (Hayek 1937, 1945). The Ostroms provided a theoretical and empirical framework for analyzing how groups self-organize to provide common-pool resources, and other economists have provided historical examples of stable private governance regimes (most notably, Stringham 2015). Though AR has the ability to push governance loci in the direction of private governance rather than public governance, it remains an empirical question whether groups of individuals who self-solve social problems using AR can sustainably displace public loci of governance. This question will be possible to address once AR has become more widespread.

\section{References}

Acemoglu, Daron. 2005. "Politics and Economics in Weak and Strong States." Journal of Monetary Economics, 52(7): 1199-1226.

Acemoglu, Daron, and James A. Robinson. 2013. "Economics versus Politics: Pitfalls of Policy Advice." Journal of Economic Perspectives, 27(2): 173-92.

Akerlof, George A. 1970. "The Market for 'Lemons': Quality Uncertainty and the Market Mechanism.” Quarterly Journal of Economics, 84(3): 488-500.

Akerlof, George A., and Robert J. Shiller. 2015. Phishing for Phools: The Economics of Manipulation and Deception. Princeton, NJ: Princeton University Press.

Arth, Clemens, Raphael Grasset, Lukas Gruber, Tobias Langlotz, Alessandro Mulloni, and Daniel Wagner. 2015. "The History of Mobile Augmented Reality." arXiv preprint arXiv:1505.01319.

Barkoczi, Daniel, and Mirta Galesic. 2016. "Social Learning Strategies Modify the Effect of Network Structure on Group Performance.” Nature Communications, 7 , article 13109.

Beito, David T. 2003. From Mutual Aid to the Welfare State: Fraternal Societies and Social Services, 1890-1967. Chapel Hill, NC: University of North Carolina Press.

BMW staff. 2017. "Mini Augmented Vision: A Revolutionary Display Concept Offering Enhanced Comfort and Safety." Press release, April 18.

Bowles, Samuel, and Sandra Polania-Reyes. 2012. "Economic Incentives and Social Preferences: Substitutes or Complements?” Journal of Economic Literature, 50(2): 368-425.

Buchanan, James M., and Gordon Tullock. 1962. The Calculus of Consent. Vol. 3. Ann Arbor: University of Michigan Press.

Buhr, Sarah. 2017. "Omega Ophthalmics Is an Eye Implant Platform with the Power of Continuous AR." TechCrunch, August 4.

Burt, Ronald S. 2009. Structural Holes: The Social Structure of Competition. Cambridge, MA: Harvard University Press.

Caudell, Thomas P., and David W. Mizell. 1992. "Augmented Reality: An Application of Heads-Up Display Technology to Manual Manufacturing Processes." Proceedings of the Twenty-Fifth Hawaii International Conference on System Sciences, (2): 659-69.

Cowper, Thomas J., and Michael E. Buerger. 2003. "Improving Our View of the World: Police and Augmented Reality Technology." Federal Bureau of Investigation. 
Cox, Michael, Gwen Arnold, and Sergio Villamayor Tomás. 2010. “A Review of Design Principles for Community-Based Natural Resource Management." Ecology and Society, 15(4): 38.

Coyne, Christopher. 2013. Doing Bad by Doing Good: Why Humanitarian Action Fails. Stanford, CA: Stanford University Press.

Coyne, Christopher, and Jayme Lemke. 2011. "Polycentricity in Disaster Relief." Studies in Emergent Orders, 3: 45-57.

Day, Lauren. 2016. "Free to Be Online Map Shows Where Women Feel Unsafe in Melbourne." ABC.net.au, December 8.

DHL staff. 2016. "DHL Rolls Out Global Augmented Reality Program." Press release, August 31.

Easley, David, and Jon Kleinberg. 2010. Networks, Crowds, and Markets: Reasoning about a Highly Connected World. Cambridge: Cambridge University Press.

Foldvary, Fred. E., and Daniel. B. Klein, eds. 2003. The Half-Life of Policy Rationales: How New Technology Affects Old Policy Issues. New York: NYU Press.

Frey, Bruno S., and Felix Oberholzer-Gee. 1997. "The Cost of Price Incentives: An Empirical Analysis of Motivation Crowding-Out." American Economic Review, 87(4): 746-55.

Gartenberg, Chaim. 2018. "Bose Is Developing Augmented Reality Glasses with a Focus on Sound." The Verge, March 9.

Gigerenzer, Gerd, Peter M. Todd, and the ABC Research Group. 1999. Simple Heuristics That Make Us Smart. Oxford: Oxford University Press.

Google. 2019. "Oceans of Data: Tracking Illegal Fishing over 1.4 Billion Square Miles.” Google Sustainability, environment projects.

Granovetter, Mark S. 1973. "The Strength of Weak Ties." American Journal of Sociology, 78(6): 1360-80.

Grossman, Sanford J., and Joseph E. Stiglitz. 1980. "On the Impossibility of Informationally Efficient Markets.” American Economic Review, 70(3): 393-408.

Hayek, Friedrich A. 1937. "Economics and Knowledge." Economica, 4(13): 33-54.

Hayek, Friedrich A. 1945. "The Use of Knowledge in Society." American Economic Review, 35(4): 519-30.

Hayek, Friedrich A. (1973) 2012. "Cosmos and Taxis." In Law, Legislation and Liberty: a New Statement of the Liberal Principles of Justice and Political Economy. London: Routledge.

Ip, Chris. 2016. "Internet of Things: The IoT Opportunity-Are You Ready to Capture a Once-in-a-Lifetime Value Pool?" Paper presented at Hong Kong Io'T Conference, June 21.

Jackson, Matthew O. 2010. Social and Economic Networks. Princeton, NJ: Princeton University Press.

Johnson, Joel. 2019. "The Past and Future of the Head-Up Display, the Original Augmented Reality." New York Magazine, January 23.

Johnson, Miles. 2015. "Hyundai Virtual Guide Introduces Augmented Reality to the Owner's Manual.” Hyundai Press Release, November 10.

Kamat, Vineet R., and Sherif El-Tawil. 2007. "Evaluation of Augmented Reality for Rapid Assessment of Earthquake-Induced Building Damage." Journal of Computing in Civil Engineering, 21(5): 303-10.

Kim, SeungJun, and Anind K. Dey. 2009. "Simulated Augmented Reality Windshield Display as a Cognitive Mapping Aid for Elder Driver Navigation." In Proceedings of the SIGCHI Conference on Human Factors in Computing Systems, 
133-42. New York: ACM.

Kim, Taeho, Sungwoo Hwang, Sangwon Kim, Hoyoung Ahn, and Daeyoung Chung, inventors. 2015. "Smart Contact Lenses for Augmented Reality and Methods of Manufacturing and Operating the Same." United States patent US 14,644,488, filed September 26, 2014, status pending.

Kirzner, Israel M. 1997. "Entrepreneurial Discovery and the Competitive Market

Process: An Austrian Approach.” Journal of Economic Literature, 35(1): 60-85.

Koopman, Christopher, Matthew D. Mitchell, and Adam D. Thierer. 2015. "The

Sharing Economy and Consumer Protection Regulation: The Case for Policy

Change.” Arlington, VA: Mercatus Center at George Mason University.

Koppl, Roger. 2018. Expert Failure. Cambridge: Cambridge University Press.

Leebmann, Johannes. 2004. "An Augmented Reality System for Earthquake

Disaster Response." In XXth ISPRS Congress, The International Archives of the Photogrammetry, Remote Sensing and Spatial Information Sciences, Istanbul.

Lueth, Knud L. 2018. "State of the IoT 2018: Number of IoT Devices Now at 7B-Market Accelerating." IOT Analytics, August 8.

Medenica, Zeljko, Andrew L. Kun, Tim Paek, and Oskar Palinko. 2011. "Augmented Reality vs. Street Views: A Driving Simulator Study Comparing Two Emerging Navigation Aids." In Proceedings of the 13th International Conference on Human Computer Interaction with Mobile Devices and Services, 265-74. New York: ACM.

Milgrom, Paul, and John Roberts. 1986. "Relying on the Information of Interested Parties." RAND Journal of Economics, 17(1): 18-32.

Murphy-Chutorian, Erik, and Mohan Manubhai Trivedi. 2010. "Head Pose Estimation and Augmented Reality Tracking: An Integrated System and Evaluation for Monitoring Driver Awareness." IEEE Transactions on Intelligent Transportation Systems, 11(2): 300-11.

Newell, Allen, and Herbert Alexander Simon. 1972. Human Problem Solving. Englewood Cliffs, NJ: Prentice Hall.

Occupational Safety and Health Administration staff. 2005. "Industrial Hygiene." Washington, DC: United States Department of Labor.

Occupational Safety and Health Administration staff. 2016. "Congressional Budget Justification: FY 2016.” Washington, DC: United States Department of Labor.

Reeson, Andrew F., and John G. Tisdell. 2008. "Institutions, Motivations and Public Goods: An Experimental Rest of Motivational Crowding." Journal of Economic Behavior \& Organization, 68(1): 273-81.

Room, Graham. 2011. Complexity, Institutions and Public Policy: Agile Decision-Making in a Turbulent $W$ orld. Cheltenham, UK: Edward Elgar.

Room, Graham. 2016. Agile Actors on Complex Terrains: Transformative Realism and Public Policy. Abingdon, UK: Routledge.

Shafer, Steven, Barry Brumitt, and Jonathan J. Cadiz. 2001. "Interaction Issues in Context-Aware Intelligent Environments." Human-Computer Interaction, 16(2): 363-378.

Shughart II, William F. 2008. "Disaster Relief as a Bad Public Good.” Symposium proceedings, from Searle Center Symposium on Bad Public Goods.

Simon, Herbert A. 1996. The Sciences of the Artificial. Cambridge, MA: MIT Press.

SpotCrime staff. 2010. "New SpotCrime iPhone App First to Offer Crime Map of Every Major US City.” Press release, January 6. 
Statt, Nick. 2017. "Elon Musk Launches Neuralink, a Venture to Merge the Human Brain with AI." The Verge, March 27.

Sullivan, Brian. 2016. "Mapping Global Fishing Activity with Machine Learning." Google Blog, September 15.

Thierer, Adam, Christopher Koopman, Anne Hobson, and Chris Kuiper. 2015. "How the Internet, the Sharing Economy, and Reputational Feedback Mechanisms Solve the Lemons Problem." University of Miami Law Review, 70 (May): 830.

Vincent, James. 2018. "Chinese Police Are Using Facial Recognition Sunglasses to Track Citizens." The Verge, February 8.

Wagner, Richard E. 2016. Politics as a Peculiar Business: Insights from a Theory of Entangled Political Economy. Cheltenham, UK: Edward Elgar.

Whitman, Glen, and Roger Koppl. 2010. "Rational Bias in Forensic Science." Law, Probability \& Risk, 9 (January): 69

Wingfield, Nick, and Mike Isaac. 2016. "Pokémon Go Brings Augmented Reality to a Mass Audience." New York Times, July 11. 